\title{
Understanding the Emotional and Informational Influence on Customer Knowledge Contribution through Quantitative Content Analysis
}

\author{
Xiaolei Wang \\ Harbin Institute of \\ Technology \\ wangxiaolei0930@163.c \\ om
}

\author{
Terence T. Ow \\ Marquette University \\ terence.ow@marquette.e \\ $\underline{\mathrm{du}}$
}

\author{
Yuqiang Feng \\ Harbin Institute of \\ Technology \\ fengyq@hit.edu.cn
}

\author{
Luning Liu \\ Harbin Institute of \\ Technology \\ liuluning@hit.edu.cn
}

\begin{abstract}
Customer knowledge contribution is a vital source of business value. Existing studies paid limited attention to emotional influence on knowledge contribution. Drawing upon social support theory, this study attempts to elaborate the influence of emotional support and informational support on knowledge contribution of customers in a firm-hosted online community. Through quantitative content analysis including product feature extraction and sentiment analysis, we analyzed content data from 2318 users. A set of research hypotheses were tested via regression analysis of panel data. We found that informational support (information diagnosticity and source credibility) and emotional support (emotional consistency and emotional difference) significantly affect customer knowledge contribution. This study contributes to knowledge contribution literature by showing the emotional and informational influence, and provides insights for community managers.
\end{abstract}

\section{Introduction}

In the digital economy, the focus of business value creation activities has been shifted from the traditional core (i.e., the enterprise itself, its core supply chain and enterprise resource planning (ERP) systems) to the enterprise edge, such as customers and online communities [1]. Customers are becoming vital sources of business value [2, 3]. Through firm-hosted online communities, they share knowledge, suggestions, usage experiences about products with employees and other customers. Dell's Ideastorm and Starbuck's My Starbucks Idea are examples of communities that collect customers' product ideas and suggestions [4, 5]. Customer knowledge contribution has been regarded as a main driver of business innovation and growth [6]. Given the importance of customer knowledge contribution, practitioners and researchers are faced with a fundamental question: How are customers motivated to contribute product knowledge in firm-hosted online communities?
To answer this question, it is necessary to understand the characteristics of user posting behaviors in firm-hosted online communities. First, user knowledge is a public good [7]. Users expect to get psychological or practical benefits from the community to compensate for their time and effort. Second, highlevel interactivity of online communications enable reciprocal relationships to be formed among users [8]. Users can easily evaluate opinions, filter information and seek better answers in online communities. Third, the postings are characterized by emotionality [9]. There are two dimensions of emotions in firm-hosted communities: emotion towards products of the firm versus emotion towards users' posting behaviors [10]. On one hand, the discussion topics in firm-hosted online communities are product-related. The messages posted by customers convey their positive or negative emotions toward the products. On the other hand, based on the reciprocal relationship network, users can seek relevant and useful information from others. They may express their positive emotions (e.g., gratitude) or negative emotions (e.g., dissatisfactory) toward others' knowledge contribution behaviors in posting messages.

Although many scholars have extensively studied the antecedents of knowledge contribution, there are some research limitations. First, prior studies mainly focused on anticipated contribution outcomes. They identified the influence factors from the perspective of psychological motivations and IT artifact designs [1114]. However, to a large extent, the emotional factors are neglected [15]. We consider the two emotional dimensions in social interactions (i.e., emotional resonance towards the products and emotional approval towards users) may both influence users' knowledge contribution. To the best of our knowledge, no prior work has empirically analyzed the impact of the emotional interactions on knowledge contribution.

Second, informational support from other users has been regarded as a highly challenging issue for sustainable user contribution [7]. Existing studies mainly illustrated this aspect using anticipated reciprocity and perceived informational help $[8,11,16]$, 
which cannot capture the practical benefits. Some studies also used the number of peers' posts or replies to measure the informational benefits $[12,13]$. However, not all messages from peers are meaningful and helpful [17]. Therefore, we measured informational benefits using quality dimensions (i.e., information diagnosticity and source credibility) and examined their effect on knowledge contribution.

Third, for research methodology, existing studies are mostly based on survey data or secondary data directly shown on the web pages, which results in lack of understanding of the posting contents. The massive amount of data collected from users' postings carries plenty of sentiment and opinions toward different product topics [18]. In this paper, we conducted quantitative content analysis to mine users' real sentiment and the quality of user generated content.

Based on the social support theory, we empirically examined how emotional support and informational support affect product knowledge contribution of customers using quantitative content analysis. This study contributes to knowledge contribution literature by highlighting the influence of emotional responses and high-quality information benefits from other users. It will also provide insights to managers concerning how to improve users' product knowledge contribution.

\section{Theoretical background and hypotheses}

\subsection{User knowledge contribution}

Two main classes of user motivation to knowledge contribution have been identified by prior studies: intrinsic and extrinsic. Intrinsic motivation focuses on the inherent satisfaction and enjoyment from the activity, while extrinsic motivation indicates goaldriven factors such as rewards and benefits [19]. We will review these antecedents and differentiate them. Table 1 shows an article summary of prior research.

On one hand, scholars have shown that satisfaction, commitment [20,21], interaction propensity, enjoying helping and self-efficacy are main underlying factors that drive them to contribute knowledge [8, 11, 20-24]. Intrinsic factors have been well-studied in online communities. They will not be included in this paper.

On the other hand, scholars identified the extrinsic antecedents based on IT artifact design practices. IT artifacts employed by online communities provide capabilities for various functions such as user selfidentification [25], formation of reciprocal knowledge sharing relationships among users [12], and facilitation of the emotional communications among users [26]. Prior studies mainly focused on the first two functionalities of IT artifacts. For example, rewards and ranks are IT-based features to facilitate verification of self-identity [7, 8, 23, 24]. Social capitals, social learning, informational value, reputation, peerrecognition, reciprocity are anticipated benefits that are derived from reciprocal relationships $[12,14,16]$.

There are several research opportunities. First, scholars paid limited attention towards the influence of emotional interactions. Hyvärinen and Beck (2018) have suggested this limitation. Based on a comprehensive literature review of the role of emotions in social media, they identified scarce research on the study of emotional factors to predict user engagement behaviors out of 82 reviewed papers [15]. Second, prior studies mainly used statistical data directly from the web pages or survey data from respondents to study extrinsic motivations without understanding the sentiment and opinions embedded in users' messages. Despite facing information overload online, users give great consideration to related, useful information and credible information source [27]. Therefore, the informational benefits factors should be explored extensively by analyzing the information content.

\subsection{Social support and knowledge contribution}

The impact of the emotional and informational influence on knowledge contribution can be explained by Social Support Theory. Social support is defined as "the exchange of verbal and nonverbal messages conveying emotion, information, or referral, to help to reduce one's uncertainty or stress" [28]. It can be regarded as social resources that are available to the person [29] and enable him feel he is being cared for and responded to by other people [30]. Emotional support and informational support have been identified as two main supportive resources [31, 32]. Some studies have suggested that emotional support and informational support are part of users' contribution motivations in virtual communities [33, 34]

2.2.1. Informational support. Informational support refers to assistance from others in the form of recommendations, advice, or knowledge [35]. Because user knowledge is a public good, users may be not willing to contribute knowledge unless they can get information benefits from others [7]. Such reciprocal relationships with other users are shown to increase relationship quality [36], increase self-efficacy [37], improve satisfaction towards the online community [22] and promote knowledge contribution [34].

However, existing studies about informational support have not paid much attention to information quality. Supportive information does not imply the high quantity of messages from others, but the related and helpful information [27]. Compared with quantity, quality are more central cues for users to determine the informational benefits [9]. The quality aspects of online information can be divided into information diagnosticity and source credibility $[38,39]$. 
Table 1. Summary of Knowledge Contribution Literature

\begin{tabular}{|c|c|c|c|c|c|}
\hline \multirow{2}{*}{ Source } & \multirow{2}{*}{ Context } & \multirow{2}{*}{$\begin{array}{l}\text { Research } \\
\text { Method }\end{array}$} & \multirow{2}{*}{ Sample } & \multicolumn{2}{|r|}{ Antecedents } \\
\hline & & & & Intrinsic & $\begin{array}{r}\text { Extrinsic } \\
\end{array}$ \\
\hline $\begin{array}{l}\text { Chiu et al. } \\
\text { (2006) [16] }\end{array}$ & $\begin{array}{l}\text { IT-oriented } \\
\text { online } \\
\text { community }\end{array}$ & Survey & 310 users & -- & $\begin{array}{l}\text { Structural factors (social interaction ties), } \\
\text { relational factors (trust, norm of reciprocity, } \\
\text { identification), cognitive factors (shared } \\
\text { language, shared vision), community-related } \\
\text { outcome expectations }\end{array}$ \\
\hline $\begin{array}{l}\text { Ma and } \\
\text { Agarwal } \\
(2007)[22]\end{array}$ & $\begin{array}{l}\text { Health-related } \\
\text { online } \\
\text { communities }\end{array}$ & Survey & 193 users & Satisfaction & $\begin{array}{l}\text { Perceived identity verfication from group } \\
\text { members }\end{array}$ \\
\hline $\begin{array}{l}\text { Wiertz and } \\
\text { Ruyter } \\
\text { (2007) [20] }\end{array}$ & $\begin{array}{l}\text { Firm-hosted } \\
\text { online } \\
\text { community }\end{array}$ & Survey & 203 users & $\begin{array}{l}\text { Commitment to the } \\
\text { community, commitment } \\
\text { to the host firm, } \\
\text { online interaction } \\
\text { propensity }\end{array}$ & -- \\
\hline $\begin{array}{l}\text { Bateman et } \\
\text { al. }(2011) \\
{[21]}\end{array}$ & $\begin{array}{l}\text { Online } \\
\text { discussion } \\
\text { community }\end{array}$ & Survey & 192 users & $\begin{array}{l}\text { Commitment to the } \\
\text { community (need, affect, } \\
\text { obligation commitment) }\end{array}$ & -- \\
\hline $\begin{array}{l}\text { Lou et al. } \\
(2013)[23]\end{array}$ & $\begin{array}{l}\text { Online Q\&A } \\
\text { community }\end{array}$ & Survey & 367 users & $\begin{array}{l}\text { Enjoying helping, } \\
\text { knowledge self-efficacy }\end{array}$ & $\begin{array}{l}\text { Rewards (rewards for quantity and for } \\
\text { quality), learning }\end{array}$ \\
\hline $\begin{array}{l}\text { Jin et al. } \\
(2015)[14]\end{array}$ & $\begin{array}{l}\text { Online Q\&A } \\
\text { community }\end{array}$ & $\begin{array}{c}\text { Statistical } \\
\text { analysis }\end{array}$ & 1006 users & 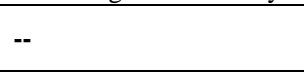 & $\begin{array}{l}\text { Identity communication, group size, peer } \\
\text { recognition, social learning }\end{array}$ \\
\hline $\begin{array}{l}\text { Cheung et al. } \\
\text { (2015) [13] }\end{array}$ & $\begin{array}{l}\text { Firm-hosted } \\
\text { online } \\
\text { community }\end{array}$ & $\begin{array}{l}\text { Statistical } \\
\text { analysis }\end{array}$ & $\begin{array}{l}6121 \text { users } \\
\text { (longitudinal) }\end{array}$ & -- & $\begin{array}{l}\text { Observational learning(peer members' } \\
\text { posting), reinforcement learning (peer } \\
\text { members' recommendation) }\end{array}$ \\
\hline $\begin{array}{l}\text { Yang et al. } \\
\text { (2016) [8] }\end{array}$ & $\begin{array}{l}\text { Firm-hosted } \\
\text { online } \\
\text { community }\end{array}$ & $\begin{array}{l}\text { Survey; } \\
\text { Statistical } \\
\text { analysis }\end{array}$ & $\begin{array}{c}892 \text { users } \\
\text { (panel), } 913 \\
\text { users (survey) }\end{array}$ & $\begin{array}{l}\text { Enjoyment in helping } \\
\text { others }\end{array}$ & $\begin{array}{l}\text { Anticipated extrinsic rewards, anticipated } \\
\text { reciprocal relationships, popularity, } \\
\text { reputation }\end{array}$ \\
\hline $\begin{array}{l}\text { Goes et al. } \\
\text { (2016) [7] }\end{array}$ & $\begin{array}{l}\text { IT oriented } \\
\text { Q\&A } \\
\text { community }\end{array}$ & $\begin{array}{l}\text { Statistical } \\
\text { analysis }\end{array}$ & $\begin{array}{l}2000 \text { users } \\
\text { (panel) }\end{array}$ & -- & User ranks \\
\hline $\begin{array}{l}\text { Zhao et al. } \\
\text { (2016) [11] }\end{array}$ & $\begin{array}{l}\text { Online Q\&A } \\
\text { community }\end{array}$ & Survey & 968 users & $\begin{array}{l}\text { Enjoyment in helping } \\
\text { others, knowledge self- } \\
\text { efficacy }\end{array}$ & -- \\
\hline $\begin{array}{l}\text { Chen et al. } \\
\text { (2018) [12] }\end{array}$ & $\begin{array}{l}\text { Online } \\
\text { discussion } \\
\text { community }\end{array}$ & $\begin{array}{l}\text { Structural } \\
\text { econometric } \\
\text { model }\end{array}$ & $\begin{array}{l}2147 \text { users } \\
\text { (panel) }\end{array}$ & ( & Reciprocity, peer recognition, self-image \\
\hline
\end{tabular}

Information diagnosticity reflects the content quality. It refers to the extent to which the presented product information can help the users to evaluate the product better [39]. By reading those information, users can understand product features and usage experiences. Therefore, information diagnosticity is sometimes measured as information helpfulness [40] and product information regarding the customer needs [39]. When users perceive that the information is diagnostic, their information needs will be satisfied, and they will be more willing to contribute in return.

Hypothesis 1. The information diagnosticity of other users' messages in the current period will positively influence the user's product knowledge contribution in the subsequent period.

Source credibility measures the extent to which a piece of information is perceived to be authentic and credible [17]. It is related to the expertise and trustworthiness of the informant [39]. When users perceive that an informant is in the position to know the truth, they will consider the information to be useful and weigh it more than other informants' messages [9]. An informant with high expertise has established the knowledge structure of products [41]. $\mathrm{He}$ is able to accurately identify the product-related problems and answer the information seeker's question. Therefore, source credibility will save the users' information-searching time and reduce information ambiguity. In this situation, users may be more willing to participate in the knowledge exchange process.

Hypothesis 2. The source credibility of received information in the current period will positively influence the user's product knowledge contribution in the subsequent period.

2.2.2. Emotional support. Emotional support refers to messages from others that contain emotional concerns such as caring, understanding, sympathy and empathy [35]. Such emotional connections relate to how online users interact with each other and may drive users' behaviors. Emotion can either refer to user's emotions toward individual activities or opinions toward products. Hyvärinen and Beck (2018) suggest opinions should be differentiated from other emotions [15]. Both types of emotion response may exert influence on customer knowledge contribution behaviors. 


\subsubsection{Emotional approval towards contribution}

behaviors. Emotions toward individual activities has been widely studied in health-related online communities. Scholars have found that users often explicitly seek emotional support from others that can motivate them to change or improve their health situations [42, 43]. Similarly, in firm-hosted online communities, users' knowledge contribution also relates to emotional responses. It is because anticipated emotional responses will always be considered into a person's decision-making process [44, 45]. Emotional approval from others towards the user's contribution behaviors means improved peer recognition, reputation and self-efficacy out of his/her expertise, which should enhance his/her contribution desires [46]. In addition, expressions of emotional approval may increase relationship quality [47] and satisfaction [48, 49], which can produce contributor's positive emotions and shape subsequent contribution behaviors [50].

Hypothesis 3. The emotional approval towards individual knowledge contribution behaviors gained from other users in the current period will positively influence the user's product knowledge contribution in the subsequent period.

2.2.2.2 Emotional Resonance towards products. In firm-hosted online communities, there are plenty of messages that convey how users evaluate a product. Some studies of emotions toward product evaluations are in the form of review ratings in electronic word-ofmouth communications [51-53]. They have shown how review valence influence other customers' perceptions of review helpfulness. Other studies have also studied emotional influence on knowledge sharing [54, 55]. They found that emotional cues in messages can facilitate users' knowledge sharing behaviors.

However, most studies mainly focused on the review emotion per se and neglected the emotion comparison among users. In the community, a focal user can express their opinions toward products by initiating a post. Then other users can review that post and express their own opinions that are similar or different from the author of the original post. We anticipate the emotional resonance from other users should influence further knowledge contribution behaviors. Emotional resonance is defined as "the emotional harmony and/or disjuncture between collective action frames and the emotional lives of potential recruits" [56]. Based on the definition, two possible resonances can be produced: directionally same and opposite opinions. We used two measures to represent the emotional resonance results: the degree of emotional consistency and the degree of emotional difference.

Emotional consistency measures whether the two parties (focal user and reviewers) have similar opinions (same polarized emotion) toward products. Altruistic behaviors is primarily facilitated by similar opinions among users [57]. Similar opinions represents a kind of agreement and support from other users. Thus, this emotional consistency could release focal users' stress [58, 59], which can be regarded as a kind of contribution goal success and further increase their contribution desires. Qiu et al. (2012) have suggested that customers are more likely to contribute productrelated information when they perceive they are consistent with opinions of others toward products [40].

Hypothesis 4. The emotional consistency towards products between the focal user and the reviewers in the current period will positively influence product knowledge contribution in the subsequent period.

To measure the extent to which opinions of two parties are different, emotional difference were calculated to measure whether other users holds more positive or negative views than the focal user toward products. Emotional valence has been the research focus for its possible influence on customer altruism behaviors $[60,61]$. Compared to positive information, users tend to be more sensitive to negative information during brand evaluation and decision-making [9]. They regard negative information as more useful information because more negative information means less ambiguity in categorizing a product as low in quality [62-64]. This is called negativity bias. Therefore, we consider more negative emotions (than the focal user's emotion) will help focal user evaluate the product better and evoke him/her more prosocial behaviors.

Hypothesis 5. When a focal user perceives his/her reviewers hold more negative emotions toward products than himself/herself in the current period, he/she will contribute more product knowledge in the subsequent period.

The overall research model is shown in Figure 1. The emotional reviews and informational benefits from other users has the potential to influence the focal user's product-related knowledge contribution.

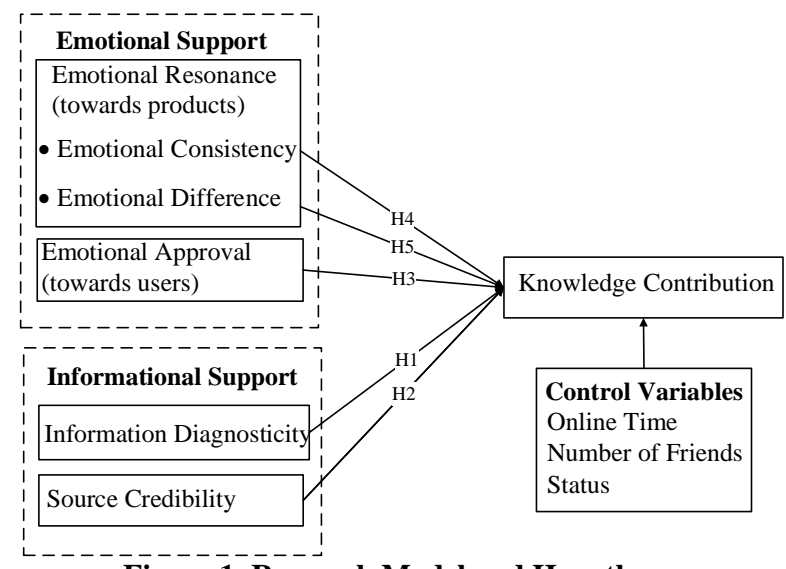

Figure 1. Research Model and Hypotheses 


\section{Research Methodology}

\subsection{Research Method}

Quantitative content analysis was used to analyze the content data. It is a research technique for objective quantitative description of content [65]. The process includes segmenting content into several units, assigning each unit to a category and providing numerical values to each category [66]. With this method, we are able to conduct product feature extraction and sentiment analysis as shown in Figure 2.

We used product feature extraction to analyze the product-related information in content. We established a dictionary to count the product-related terminologies. We then used existing electronic product glossaries from a Chinese search engine platform named Sougou (https://pinyin.sogou.com/dict). In addition, colloquial words, synonyms, and unique words in our studied community are extracted from messages by official administrators that introduce product features. Using tf-idf algorithm in Python, we computed the weight of each word in those posts and sort out the important technical noun words [67].

In addition, we conducted sentiment analysis to mine emotions underlying in these messages. For content analysis of Chinese, many research institutions provide well-classified word dictionaries. Our emotion dictionaries (including positive/negative adjectives and adverbs) were adapted from National Taiwan University Sentiment Dictionary (NTUSD) [68] and Hownet lexicon from CNKI platform (a Chinese knowledge management platform) [69]. For each message, we cut it into sub-sentences using punctuations. For each sub-sentence, we further computed its emotion score (both positive score and negative score). This is consistent with Cheung and Thadani's suggestion that messages are sometimes two-sided and contain both positive and negative elements [9]. By summarizing all positive scores and negative scores of sub-sentences, we obtain net emotion score for each sentence. When computing the emotion score, we weighted some adjectives based on the existence of specified adverbs, exclamation point and privative words. For example, there is a message "It is pretty. However, it is expensive, and it is the most useless product I've ever used.". The emotion score of the first sub-sentence equals 1 because there is one positive word pretty. The emotion score of the second sub-sentence is (-1) because of the negative word expensive. The negative score of the word useless in the third sub-sentence is weighted twice because of the adverb word most (i.e., the emotion score equals 2). Then the net emotion score of the whole message is $(1-1-2=-2)$. In this way, we analyzed emotions in all forms of messages of sample users including posts, replies and reviews.

\subsection{Data Collection}

The panel data used in this article was collected from Xiaomi's online community named as MIUI community (http://www.miui.com/). Xiaomi was established in 2010 and has been a top-5 smartphone manufacturer in China. It repeatedly attributes its rapid growth and success to customers' knowledge contribution in product development and improvement. MIUI is one of its software products. Customers in MIUI community can report product bugs, suggest possible solutions, discuss product features, and share usage perceptions and experiences.

We developed a Python program to collect panel data of users. Our sample users is from an active user group named inner testing group in this community. They are selected by the community administrators based on their status points. This allows us to focus on active users and understand their behaviors. Also, this mitigates possible estimation bias from inactive group [7]. We first randomly chose 2515 users and tracked their weekly activities from January 7, 2018 to March 13, 2018. In total, 9 time-period panel data were collected. After filtering out users with incomplete data, 2318 users were used in this research. In addition, we also tracked their complete activity history (including 129167 posts and 1442041 replies) and all reviews to their posts (3577020 reviews) for content analysis.

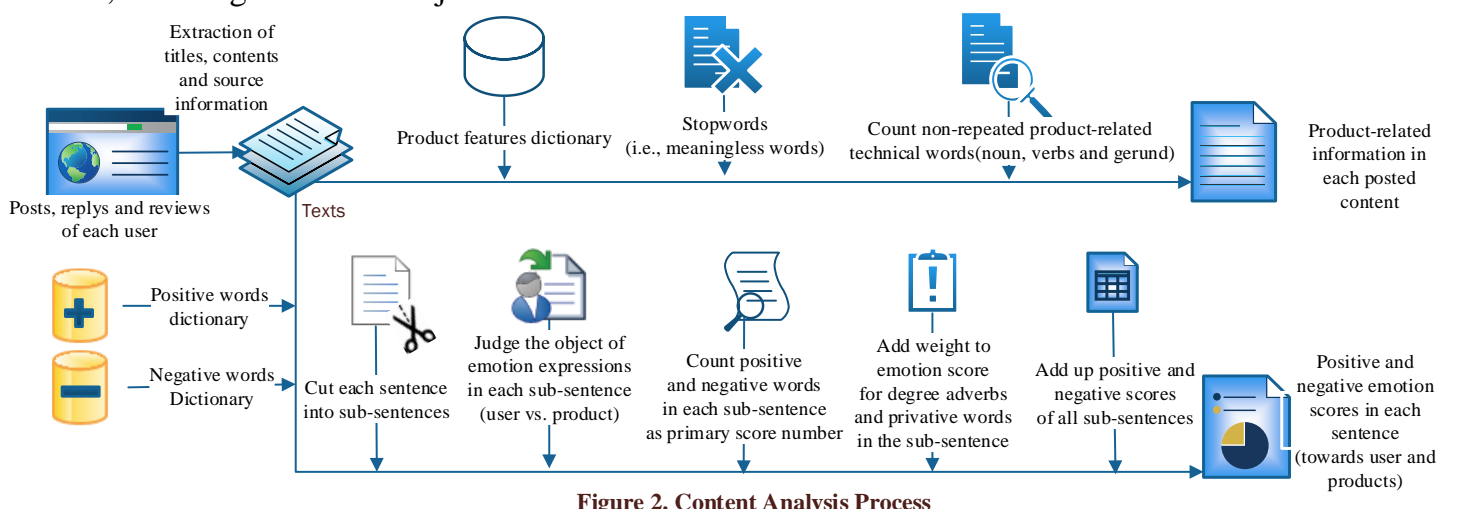




\subsection{Variable Measures}

3.3.1. Dependent variable. Based on Marchi et al. (2011) [70], we computed user's product knowledge contribution as the number of product-related technical words in user's initiated posts (Knowledge $i t, i=1,2, \ldots$, $2318, \mathrm{t}=1,2, \ldots 9)$. This is a reasonable way to identify whether the user is posting product-related information because product-related technical terms are a kind of common language in the community. Using feature extraction analysis, 7372 technical words are included in the dictionary. Based on this dictionary, we used text-retrieval technique in Python language to compute the number of non-repeated technical terms that appeared in users' posts.

3.3.2. Independent variables. For information diagnosticity, it was accessed using informativeness [39] and helpfulness [40]. Informativeness measures necessary information offered by other users [9]. We calculated it as the number of product-related terms contained in focal user's received reviews in the logarithmic form $\left(\ln \operatorname{Info} o_{i, t-1}\right)$. We refer to the product feature dictionary and count the number of terms by traversing the review content. In addition, helpfulness was measured as the number of positive evaluations given by the focal user towards other users' contribution behaviors $\left(\mathrm{Help}_{i, t-1}\right)$.

For source credibility, it is difficult to judge credibility of users except for the employees. In MIUI community, internal employees are registered users (labeled as developer or administrator) to answer questions of customers. Therefore, we used the number of bug report posts answered by employees as a gauge to represent the extent to which the information source are credible (Credit $\left.t_{i t-1}\right)$.

For emotional approval towards the focal user (Approval ${ }_{i, t-1}$ ), we used the ratio of reviews with positive emotions toward the user in all reviews.

The measures of emotional resonance towards products should be computed by each post. This is because each post contains a net emotion score towards products (the scores can be 0). The emotions in reviews is then compared with emotion score of the original post.

For emotional consistency, we first computed the net emotion score (positive score - negative score) of each post and each review. Then for each post, we computed the number of reviews with same direction emotional signs to the sign of the post. Finally we summarized the numbers of reviews with same signs in all posts. As shown in Formula (1), $N_{i, t-1}$ is the number of initiated posts up to time period $(t-1)$ of focal user $i$.

$$
\text { Consistency }_{i, t-1}=\sum_{j=1}^{N_{i, t-1}} \text { SameSignReviewNum }{ }_{i, j, t-1}
$$

For emotional difference (EmoDiff $f_{i, t-1}$ ), we used upward emotional difference to represent to what extent the emotion of the review is higher than the emotion of the original post. By aggregating upward emotional differences of all posts, we computed the overall upward emotional difference as shown in Formula (2). $N_{i, t-1}$ is the post number of user $i$ up to time period $(t-1)$. For post $j$ of user $i, M_{i j, t-1}$ is the review number of post $j$ up to time period $(t-1)$. For each review $k$ to the post $j$ of user $i$, diff $f_{i j k}$ is the upward emotional difference between review $k$ and the post $j$ (i.e., emotion score of the review $k$ - emotion score of the post $j$ ).

This formula computes the average emotional difference of all posts. For example, user $i$ have two posts in time period $(t-1)$. The net emotion scores in those two posts are both (-2). The first post received reviews with emotion scores $\{1,2,3\}$, and the second post received reviews with scores $\{-1,-2,-3,1,2,3\}$. The total upward difference of the first post is $(3+4+5=12)$. Similarly, the value of the second post is also 12. However, it is obvious that the review emotions in the first post is more positive than the second post. Therefore, we use averaged emotional difference value to represent the difference value of each post. The averaged value of the first post is $(12 / 3=4)$. The averaged value of the second post is $(12 / 6=2)$. Finally, for the two posts, the emotional difference is $((4+2) / 2=3)$, which implies on the whole reviewers hold more positive emotions (3 scores higher) than user $i$.

$$
\text { EmoDiff }_{i, t-1}=\left\{\sum_{j=1}^{N_{i, t-1}}\left[\left(\sum_{k=1}^{M_{i, t-1}} \operatorname{diff}_{i j k}\right) / M_{i j, t-1}\right]\right\} / N_{i, t-1}
$$

Prior studies have suggested the influence of incentive and social network on knowledge contribution [14, 23]. Therefore, we controlled such variables. Users in MIUI community can accumulate status scores by participating in online activities. The status value (lnStatus $\left.{ }_{i, t-1}\right)$ represents the formal recognition of user contribution. Furthermore, MIUI community provides each member's cumulative online time $\left(O T_{i, t-1}\right)$. It reflects participation duration of users. In addition, users can establish friendship relationship with other users through Request-Confirmation mechanism. This relationship is represented as a control variable (Friend $i, t-1)$.

Table 2 shows the variable descriptions and the pairwise correlations. Our research model is shown in Equation (3). $\beta_{i}$ are the coefficient estimates. $u_{i}$ is the unobserved heterogeneity. $v_{i, t}$ is the idiosyncratic error.

$$
\begin{aligned}
\text { Knowledge }_{i t}= & \beta_{1} \text { InInfo }_{i, t-1}+\beta_{2} \text { Help }_{i, t-1}+\beta_{3} \text { Credit }_{i, t-1}+ \\
& \beta_{4} \text { Approval }_{i, t-1}+\beta_{5} \text { Consistency }_{i, t-1}+\beta_{6} \text { EmoDiff }_{i, t-1} \\
& \beta_{7} \text { InStatus }_{i, t-1}+\beta_{8} O_{i, t-1}+\beta_{9} \text { Friend }_{i, t-1}+u_{i}+v_{i, t}
\end{aligned}
$$


Table 2. Descriptive Statistics and Pearson Correlations

\begin{tabular}{|c|c|c|c|c|c|c|c|c|c|c|c|}
\hline & $\operatorname{Mean}(S . D)$. & 1 & 2 & 3 & 4 & 5 & 6 & 7 & 8 & 9 & 10 \\
\hline Knowledge $_{i t}$ & $\begin{array}{l}296.455 \\
(1449.701)\end{array}$ & 1.000 & & & & & & & & & \\
\hline $\ln \operatorname{Info} o_{i, t-1}$ & $\begin{array}{l}4.917 \\
(1.622)\end{array}$ & $0.276^{*}$ & 1.000 & & & & & & & & \\
\hline Help $_{i, t-1}$ & $\begin{array}{l}133.025 \\
(336.224)\end{array}$ & $0.175^{*}$ & $0.231 *$ & 1.000 & & & & & & & \\
\hline Credit $_{i, t-1}$ & $\begin{array}{l}4.833 \\
(9.616)\end{array}$ & $0.121 *$ & $0.270^{*}$ & $0.113^{*}$ & 1.000 & & & & & & \\
\hline Approval $_{i, t-1}$ & $\begin{array}{l}0.166 \\
(0.097)\end{array}$ & $0.084 *$ & $0.088^{*}$ & $0.117 *$ & $0.021 *$ & 1.000 & & & & & \\
\hline Consistency $_{i, t-1}$ & $\begin{array}{l}103.970 \\
(604.174) \\
\end{array}$ & $0.498 *$ & $0.389^{*}$ & $0.191^{*}$ & $0.031 *$ & $0.138^{*}$ & 1.000 & & & & \\
\hline EmoDiff $_{i, t-1}$ & $\begin{array}{l}-0.043 \\
(0.936)\end{array}$ & $-0.260 *$ & $-0.196 *$ & $-0.117 *$ & $0.026^{*}$ & $-0.147 *$ & $-0.271 *$ & 1.000 & & & \\
\hline lnStatus $_{i, t-1}$ & $\begin{array}{l}8.231 \\
(0.726)\end{array}$ & $0.228^{*}$ & $0.444^{*}$ & $0.293^{*}$ & $0.406^{*}$ & $0.083^{*}$ & $0.205^{*}$ & $-0.115^{*}$ & 1.000 & & \\
\hline$O T_{i, t-1}$ & $\begin{array}{l}106.501 \\
(238.135)\end{array}$ & $0.223 *$ & $0.267 *$ & $0.296^{*}$ & $0.252 *$ & $0.141^{*}$ & $0.247 *$ & $-0.125 *$ & $0.433 *$ & 1.000 & \\
\hline Friend $_{i, t-1}$ & $\begin{array}{l}0.889 \\
(8.701)\end{array}$ & $0.367 *$ & $0.172 *$ & $0.268^{*}$ & $0.072 *$ & $0.123^{*}$ & $0.297 *$ & $-0.196^{*}$ & $0.232 *$ & $0.389 *$ & 1.000 \\
\hline
\end{tabular}

\section{Data Analysis and Results}

The Hausman test showed that fixed effect model (FEM) is more appropriate than random effect model (REM) $(p<0.001)$. F test further showed FEM is preferred over the mixed effect model $(p<0.001)$. Therefore, we chose to run FEM model. In addition, the modified Wald test revealed group-wise heteroskedasticity $(p<0.001)$. The Wooldridge test revealed there is first-order autocorrelation in panel data $(p<0.001)$. To get the valid estimators, we used the cluster-robust standard errors [71]. FEM regression results are shown in Table 3.

Table 3. Results of Fixed Effect Model Regression

\begin{tabular}{llc}
\hline Variables & \multicolumn{1}{c}{$\beta$} & S.E. \\
\hline Intercept & $182.634 * * *$ & 17.897 \\
OT $_{i, t-1}$ & 4.440 & 3.008 \\
InStatus $_{i, t-1}$ & $14.098^{* * * *}$ & 2.172 \\
Friend $_{i, t-1}$ & 64.249 & 39.486 \\
InInfo $_{i, t-1}$ & $31.932 * * *$ & 7.461 \\
Help $_{i, t-1}$ & $65.827 * * *$ & 20.606 \\
Credit $_{i, t-1}$ & $61.200 * * *$ & 11.947 \\
Approval $_{i, t-1}$ & -2.447 & 4.525 \\
Consistency $_{i, t-1}$ & $33.419 * *$ & 14.354 \\
EmoDiff $_{i, t-1}$ & $-29.253^{* *}$ & 12.623 \\
$R^{2}($ within $)$ & $0.238^{* * *}$ & \\
\hline$* p<0.1, * * p<0.05 ; * * * p<0.01$ & & \\
\hline
\end{tabular}

For control variables, the results showed that the users with higher status points were more likely to contribute to product knowledge. In addition, the influence of online time and friend number were insignificant as control variables.

Our results confirmed the influence of informational support. First, users who receive more product-related information from other users appeared to make more product knowledge contribution in the subsequent week $\left(\beta_{1}=31.932, p<0.01\right)$. Also, users receiving more helpful information were found to contribute more knowledge in return $\left(\beta_{2}=65.827, p<0.01\right)$. Thus, hypothesis $\mathrm{H} 1$ was validated.

Users receiving more answers to their bug report posts from credible employees also contributed more subsequently, supporting $\mathrm{H} 2\left(\beta_{3}=61.200, p<0.01\right)$. For emotional support, our results showed the insignificant relationship between others' emotional approval towards the focal user's contribution behaviors $(p>0.1)$. Thus, $\mathrm{H} 3$ was not supported.

Emotional resonance towards products from other users were found to have significant influence on user knowledge contribution. More consistent opinions from other users appeared to encourage the focal users' knowledge contribution, validating $\mathrm{H} 4 \quad\left(\beta_{5}=33.419\right.$, $p<0.05)$. Moreover, when reviewers hold emotions that are more negative than the focal users, the focal users were more willing to make contributions, which supported H5 ( $\left.\beta_{6}=-29.253, p<0.05\right)$.

To ensure our results are robust, we conducted analyses with different sample size $(1000,1500,2000)$. The significance of each coefficients was consistent, indicating that our model is robust.

\section{Discussion}

\subsection{Theoretical contributions and implications}

The study contributes to knowledge contribution literature by examining the influence of informational support and emotional support. Overall, we analyzed the antecedent roles of informational and emotional support. This is consistent with the implications in response theory and regulation theory. In response theory, Horowitz et al. (2001) identified agentic responses (i.e., information and advice) and communal responses (i.e., empathy and understanding) are two important dimensions of listeners' responses that can produce positive personal feelings [72]. In addition, in 
identified interpersonal affect regulation strategies, cognitive engagement strategies involve getting advice, whereas affective engagement strategies relate to emotion expressions [73]. Our findings provide supporting evidence to these theories.

For informational support, we found that diagnostic information from other users can facilitate user product knowledge contribution. Zhao et al. (2013) have suggested conscious deliberation is likely to guide user future contribution behaviors. Users tend to evaluate the benefits of behaviors especially the information benefits [74]. Similarly, based on social exchange theory, users tend to reward other users for their assistance by contributing knowledge [75].

Information credibility was found to positively affect user knowledge contribution. In the firm-hosted online community, employees especially the product developers are the most credible users. When users perceive product failure, they tends to produce antisocial behaviors [76]. At that moment, employees can accurately identify needs/problems of customers, and improve customer satisfaction and value [77]. Our results confirmed that when employees reply to more bug report posts, users tend to contribute more knowledge to the community.

For emotional support, this paper identified the different influence of emotional responses toward users and emotional responses toward products. On one hand, emotional approval from other users represents their recognition of the user contribution behaviors. It was found to have no influence on subsequent contribution behaviors of focal users. The reason for that could be explained by the technology artifact design of our studied community. In MIUI community, positive emotional expressions of contribution behaviors from other users cannot bring more reputation or status value than other non-emotional reviews. Sutanto and Jiang (2013) have suggested that rating of contributed knowledge from other users may have no influence on continuous knowledge contribution because reputation is much more important than user feedback. They provide support for our results [46].

On the other hand, emotional resonance towards products from others was shown to significantly affect knowledge contribution behaviors. First, consistent opinions from others are a kind of agreement and support of focal user's opinion, which can narrow the distance between the users. This result confirmed the work by $\mathrm{Yu}$ and $\mathrm{Chu}$ (2007) that affection similarity can produce voluntary contribution [78].

Second, the upward emotional difference was shown to be negatively related to knowledge contribution. That implies when the focal user perceives others that hold more negative emotions, the focal user is more likely to contribute knowledge. Although existing studies have already shown the negativity bias (users pay more attention to negative emotions), they may have not taken in consideration and neglected the focal user's prior impression of products. We emphasize that this bias can also exist after emotion comparisons and users are sensitive to more negative emotions than themselves. This can be explained by the perceived information helpfulness. More negative information implies less ambiguity in the product quality evaluation, which provides more reference value for users [64].

Overall, our research makes contributions to knowledge contribution literature in several ways. First, we identified informational support and emotional support as antecedents of product knowledge contribution. Existing literature has paid limited attention to emotional factors. Specially, we examined how emotion responses from other users influence users' subsequent behaviors. Second, we used quantitative content analysis to deeply mine users' emotions underlying the messages. This method of data collection allows us to measure the quality aspects of messages. In this way, we combine qualitative and quantitative methods in one study and more precisely examined the role of informational and emotional support. Third, our findings indicate that emotional resonance towards products is more important than emotional approval of users' behaviors.

Our study provides some practical implications for firm-hosted community managers. First, when it comes to the technology artifact design, managers should not only focus on reputation-based or membership-based mechanism, they should also pay attention to informational and emotional interactions among users. Attention is also needed to ensure employee-customer interactions because employees can also play an important role in facilitating user contribution. This study provides guidance for managers about how to facilitate users' knowledge contribution.

\subsection{Limitations and future research}

There are several limitations in this study. First, we used the user's knowledge in initiated posts as dependent variable, which cannot capture the differences between post behaviors and reply behaviors. We believe that post and reply behaviors are influenced by different factors. This can be explored in future research. Second, the present study is conducted in a single firm-hosted community. Analyses with multiple firms are needed to generalize our findings.

\section{Conclusion}

Customers have increasingly become value cocreator of firms by contributing knowledge to their products or services. The prior literature has not paid adequate attention to emotional antecedents. Based on 
social support theory, this study analyzed data using quantitative content analysis method and found significant influence of informational support and emotional support on product knowledge contribution. Specifically, we demonstrated the important role of emotional resonance from other users. This research provides both theoretical and managerial implications.

\section{Acknowledgements}

This research was supported by the National Natural Science Foundation of China (\#71429001, \#71472053, \#91646105, \#71781220619); the Postdoctoral Science Foundation of China (\#2014M550198, 2015T80363); and the China Scholarship Council (\#201706120224).

\section{References}

[1] P. Gray, O.A. El Sawy, G. Asper, M. Thordarson, Realizing Strategic Value Through Center-Edge Digital Transformation in Consumer-Centric Industries, MIS Quarterly Executive, 12 (2013).

[2] R.T. Rust, M.-H. Huang, Handbook of service marketing research, Edward Elgar Publishing, 2014.

[3] P. Leeflang, Paving the way for "distinguished marketing", International Journal of Research in Marketing, 28 (2011) 76-88.

[4] B.L. Bayus, Crowdsourcing new product ideas over time: An analysis of the Dell IdeaStorm community, Management science, 59 (2013) 226-244.

[5] A.Y. Chua, S. Banerjee, Customer knowledge management via social media: the case of Starbucks, Journal of Knowledge Management, 17 (2013) 237-249.

[6] D. Kyoon Yoo, Substructures of perceived knowledge quality and interactions with knowledge sharing and innovativeness: a sensemaking perspective, Journal of Knowledge Management, 18 (2014) 523-537.

[7] P.B. Goes, C. Guo, M. Lin, Do incentive hierarchies induce user effort? Evidence from an online knowledge exchange, Information Systems Research, 27 (2016) 497-516.

[8] J. Yang, C.L. Sia, L. Liu, H. Chen, Sellers versus buyers: differences in user information sharing on social commerce sites, Information Technology \& People, 29 (2016) 444-470.

[9] C.M. Cheung, D.R. Thadani, The impact of electronic word-ofmouth communication: A literature analysis and integrative model, Decision support systems, 54 (2012) 461-470.

[10] W. Jabr, E. Zheng, Know yourself and know your enemy: An analysis of firm recommendations and consumer reviews in a competitive environment, MIS Quarterly, 38 (2013) 20-67.

[11] L. Zhao, B. Detlor, C.E. Connelly, Sharing knowledge in social Q\&A sites: the unintended consequences of extrinsic motivation, Journal of Management Information Systems, 33 (2016) 70-100.

[12] W. Chen, X. Wei, K. Zhu, Engaging Voluntary Contributions in Online Communities: A Hidden Markov Model, Mis Quarterly, 42 (2018).

[13] C.M. Cheung, I.L. Liu, M.K. Lee, How online social interactions influence customer information contribution behavior in online social shopping communities: a social learning theory perspective, Journal of the Association for Information Science and Technology, 66 (2015) 2511-2521.

[14] J. Jin, Y. Li, X. Zhong, L. Zhai, Why users contribute knowledge to online communities: An empirical study of an online social Q\&A community, Information \& management, 52 (2015) 840849.

[15] H. Hyvärinen, R. Beck, Emotions Trump Facts: The Role of Emotions in on Social Media: A Literature Review, in: Proceedings of the 51st Hawaii International Conference on System Sciences, 2018.
[16] C.-M. Chiu, M.-H. Hsu, E.T. Wang, Understanding knowledge sharing in virtual communities: An integration of social capital and social cognitive theories, Decision support systems, 42 (2006) 18721888.

[17] G. Wang, X. Liu, W. Fan, A knowledge adoption model based framework for finding helpful user-generated contents in online communities, Thirty Second International Conference on Information Systems, Shanghai (2011).

[18] X. Hu, L. Tang, J. Tang, H. Liu, Exploiting social relations for sentiment analysis in microblogging, in: Proceedings of the sixth ACM international conference on Web search and data mining, ACM, 2013, pp. 537-546.

[19] H.-F. Lin, Effects of extrinsic and intrinsic motivation on employee knowledge sharing intentions, Journal of information science, 33 (2007) 135-149.

[20] C. Wiertz, K. de Ruyter, Beyond the call of duty: Why customers contribute to firm-hosted commercial online communities, Organization studies, 28 (2007) 347-376.

[21] P.J. Bateman, P.H. Gray, B.S. Butler, Research note-the impact of community commitment on participation in online communities, Information Systems Research, 22 (2011) 841-854.

[22] M. Ma, R. Agarwal, Through a glass darkly: Information technology design, identity verification, and knowledge contribution in online communities, Information systems research, 18 (2007) 4267.

[23] J. Lou, Y. Fang, K.H. Lim, J.Z. Peng, Contributing high quantity and quality knowledge to online Q\&A communities, Journal of the Association for Information Science and Technology, 64 (2013) 356-371.

[24] J. Lou, K.H. Lim, Y. Fang, J.Z. Peng, Drivers Of Knowledge Contribution Quality And Quantity In Online Question And Answering Communities, in: PACIS, 2011, pp. 121.

[25] L. Khansa, X. Ma, D. Liginlal, S.S. Kim, Understanding members' active participation in online question-and-answer communities: A theory and empirical analysis, Journal of Management Information Systems, 32 (2015) 162-203.

[26] L. Dang-Xuan, S. Stieglitz, Impact and Diffusion of Sentiment in Political Communication-An Empirical Analysis of Political Weblogs, in: ICWSM, 2012.

[27] A. Worrall, S. Oh, Place of Health Information and SocioEmotional Support in Social Questioning and Answering, Information Research, 18 (2013).

[28] J.B. Walther, S. Boyd, Attraction to computer-mediated social support, Communication technology and society: Audience adoption and uses, 153188 (2002).

[29] B.H. Gottlieb, A.E. Bergen, Social support concepts and measures, Journal of psychosomatic research, 69 (2010) 511-520.

[30] S. Cobb, Social support as a moderator of life stress, Psychosomatic medicine, (1976).

[31] K.-Y. Huang, P. Nambisan, Ö. Uzuner, Informational Support or Emotional Support: Preliminary Study of an Automated Approach to Analyze Online Support Community Contents, in: ICIS, 2010, pp. 210

[32] M.N. Hajli, A study of the impact of social media on consumers, International Journal of Market Research, 56 (2014) 387-404.

[33] M.S. Rosenbaum, C.A. Massiah, When customers receive support from other customers: Exploring the influence of intercustomer social support on customer voluntary performance, Journal of Service Research, 9 (2007) 257-270.

[34] H.J. Ye, Y. Feng, B.C. Choi, Understanding knowledge contribution in online knowledge communities: A model of community support and forum leader support, Electronic Commerce Research and Applications, 14 (2015) 34-45.

[35] T.-P. Liang, E. Turban, Introduction to the special issue social commerce: a research framework for social commerce, International Journal of electronic commerce, 16 (2011) 5-14.

[36] M.N. Hajli, The role of social support on relationship quality and social commerce, Technological Forecasting and Social Change, 87 (2014) 17-27. 
[37] C.-M. Chiu, H.-Y. Huang, H.-L. Cheng, P.-C. Sun, Understanding online community citizenship behaviors through social support and social identity, International journal of information management, 35 (2015) 504-519.

[38] S. Karimi, F. Wang, Online review helpfulness: Impact of reviewer profile image, Decision Support Systems, 96 (2017) 39-48.

[39] X. Wang, K.-K. Wei, H.-H. Teo, The Acceptance of Product Recommendations from Web-Based Word-of-Mouth Systems: Effects of Information, Informant and System Characteristics, ICIS 2007 Proceedings, (2007) 93.

[40] L. Qiu, J. Pang, K.H. Lim, Effects of conflicting aggregated rating on eWOM review credibility and diagnosticity: The moderating role of review valence, Decision Support Systems, 54 (2012) 631-643.

[41] G.L. Murphy, J.C. Wright, Changes in conceptual structure with expertise: Differences between real-world experts and novices, Journal of Experimental Psychology: Learning, Memory, and Cognition, 10 (1984) 144.

[42] Y. Zhang, D. He, Y. Sang, Facebook as a platform for health information and communication: a case study of a diabetes group, Journal of medical systems, 37 (2013) 9942.

[43] K.O. Hwang, A.J. Ottenbacher, A.P. Green, M.R. Cannon-Diehl, O. Richardson, E.V. Bernstam, E.J. Thomas, Social support in an Internet weight loss community, International journal of medical informatics, 79 (2010) 5-13.

[44] R.P. Bagozzi, R. Pieters, Goal-directed emotions, Cognition \& Emotion, 12 (1998) 1-26.

[45] R.P. Bagozzi, U.M. Dholakia, Antecedents and purchase consequences of customer participation in small group brand communities, International Journal of research in Marketing, 23 (2006) 45-61.

[46] J. Sutanto, Q. Jiang, Knowledge seekers' and contributors' reactions to recommendation mechanisms in knowledge management systems, Information \& management, 50 (2013) 258-263.

[47] Y. Wang, M. Hajli, Co-creation in branding through social commerce: The role of social support, relationship quality and privacy concerns, Twentieth Americas Conference on Information Systems, Savannah (2014).

[48] T. Hennig - Thurau, K.P. Gwinner, G. Walsh, D.D. Gremler, Electronic word - of - mouth via consumer - opinion platforms: What motivates consumers to articulate themselves on the Internet?, Journal of interactive marketing, 18 (2004) 38-52.

[49] G.A. Van Kleef, The emerging view of emotion as social information, Social and Personality Psychology Compass, 4 (2010) 331-343.

[50] H.-T. Tsai, R.P. Bagozzi, Contribution Behavior in Virtual Communities: Cogntiive, Emotional, and Social Influences, MIS Quarterly, 38 (2014).

[51] Q. Ye, R. Law, B. Gu, W. Chen, The influence of usergenerated content on traveler behavior: An empirical investigation on the effects of e-word-of-mouth to hotel online bookings, Computers in Human behavior, 27 (2011) 634-639.

[52] A.G. Mauri, R. Minazzi, Web reviews influence on expectations and purchasing intentions of hotel potential customers, International Journal of Hospitality Management, 34 (2013) 99-107.

[53] S.N. Ahmad, M. Laroche, How do expressed emotions affect the helpfulness of a product review? Evidence from reviews using latent semantic analysis, International Journal of Electronic Commerce, 20 (2015) 76-111.

[54] T. Araujo, P. Neijens, R. Vliegenthart, What Motivates Consumers To Re-Tweet Brand Content?: The impact of information, emotion, and traceability on pass-along behavior, Journal of Advertising Research, 55 (2015) 284-295.

[55] J. Berger, K.L. Milkman, What makes online content viral?, Journal of marketing research, 49 (2012) 192-205.

[56] D. Schrock, D. Holden, L. Reid, Creating emotional resonance: Interpersonal emotion work and motivational framing in a transgender community, Social Problems, 51 (2004) 61-81.
[57] K. Sole, J. Marton, H.A. Hornstein, Opinion similarity and helping: Three field experiments investigating the bases of promotive tension, Journal of Experimental Social Psychology, 11 (1975) 1-13.

[58] S.T. Fiske, S.E. Taylor, Social cognition: From brains to culture, Sage, 2013.

[59] S.S. Townsend, H.S. Kim, B. Mesquita, Are you feeling what I'm feeling? Emotional similarity buffers stress, Social Psychological and Personality Science, 5 (2014) 526-533.

[60] J.A. Ruth, F.F. Brunel, C.C. Otnes, Linking thoughts to feelings: Investigating cognitive appraisals and consumption emotions in a mixed-emotions context, Journal of the Academy of Marketing Science, 30 (2002) 44-58.

[61] I.E. de Hooge, Predicting consumer behavior with two emotion appraisal dimensions: Emotion valence and agency in gift giving, International Journal of Research in Marketing, 31 (2014) 380-394.

[62] P.M. Herr, F.R. Kardes, J. Kim, Effects of word-of-mouth and product-attribute information on persuasion: An accessibilitydiagnosticity perspective, Journal of consumer research, 17 (1991) 454-462.

[63] C. Park, T.M. Lee, Information direction, website reputation and eWOM effect: A moderating role of product type, Journal of Business research, 62 (2009) 61-67.

[64] C.-C. Wang, M.-Z. Li, Y.Y. Yang, Perceived Usefulness of Word-of-Mouth: An Analysis of Sentimentality in Product Reviews, in: International Conference on Multidisciplinary Social Networks Research, Springer, 2015, pp. 448-459.

[65] B. Berelson, Content analysis in communication research, (1952).

[66] L. Rourke, T. Anderson, Validity in quantitative content analysis, Educational Technology Research and Development, 52 (2004) 5 .

[67] L.-P. Jing, H.-K. Huang, H.-B. Shi, Improved feature selection approach TFIDF in text mining, in: Machine Learning and Cybernetics, 2002. Proceedings. 2002 International Conference on, IEEE, 2002, pp. 944-946.

[68] L.W. Ku, H.H. Chen, Mining opinions from the Web: Beyond relevance retrieval, Journal of the American Society for Information Science and Technology, 58 (2007) 1838-1850.

[69] Y.-L. Zhu, J. Min, Y.-q. Zhou, X.-j. Huang, L.-D. Wu, Semantic orientation computing based on HowNet, Journal of Chinese Information Processing, 20 (2006) 14-20.

[70] G. Marchi, C. Giachetti, P. De Gennaro, Extending lead-user theory to online brand communities: The case of the community Ducati, Technovation, 31 (2011) 350-361.

[71] A.C. Cameron, P.K. Trivedi, Microeconometrics using stata, Stata press College Station, TX, 2010.

[72] L.M. Horowitz, E.N. Krasnoperova, D.G. Tatar, M.B. Hansen, E.A. Person, K.L. Galvin, K.L. Nelson, The way to console may depend on the goal: Experimental studies of social support, Journal of Experimental Social Psychology, 37 (2001) 49-61.

[73] K. Niven, P. Totterdell, D. Holman, A classification of controlled interpersonal affect regulation strategies, Emotion, 9 (2009) 498.

[74] K. Zhao, A.C. Stylianou, Y. Zheng, Predicting users' continuance intention in virtual communities: The dual intentionformation processes, Decision Support Systems, 55 (2013) 903-910. [75] P. Blau, Exchange and power in social life, Routledge, 2017.

[76] M. Groth, A. Grandey, From bad to worse: Negative exchange spirals in employee-customer service interactions, Organizational Psychology Review, 2 (2012) 208-233.

[77] C. Homburg, J. Wieseke, T. Bornemann, Implementing the marketing concept at the employee-customer interface: the role of customer need knowledge, Journal of Marketing, 73 (2009) 64-81.

[78] C.-P. Yu, T.-H. Chu, Exploring knowledge contribution from an OCB perspective, Information \& Management, 44 (2007) 321-331. 